\title{
Should dentists be braced for \\ HMRC to tighten the (self-employment) gap?
}

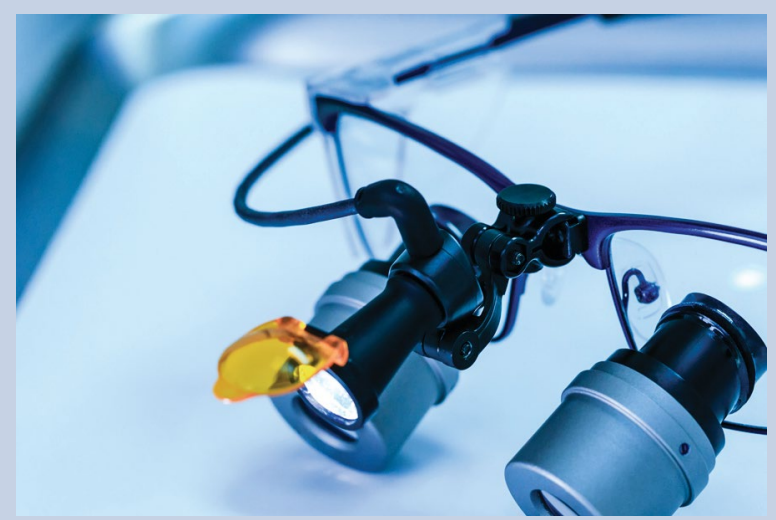

There has been a lot of focus over the last few years on the employment status of self-employed contractors, with the changes to the IR35 regulations and the landmark Uber case earlier this year.

Dentists have, so far, escaped the scrutiny of an employment status review by HMRC, relying on the standard British Dental Association (BDA) and Dental Practitioners Association (DPA) agreements to ensure the income of dentists practising as associates is assessable under trading income rules and not as employment income.

HMRC have recently announced that, with effect from April 2023, they will withdraw the paragraph in their guidance which mentions the BDA and DPA standard associate agreements.

\section{What does this mean for the numerous associate dentists} subject to UK tax law?

It does not mean that all associate dentists are suddenly going to be subject to tax and NIC deductions as though they were employees, or that every associate is going to be subject to an HMRC enquiry into their status. This is not a change to the principles of self-employment status, but it does mean that we should not assume that the status quo will prevail.

It would be prudent to take this opportunity, in advance of April 2023, to review your associate engagements and use HMRC's CEST [Check Employment Status for Tax] toolkit to make a determination of your associate engagements and review their daily working practices: https://www.gov.uk/guidance/ check-employment-status-for-tax.

We may well see a more formalised requirement for practices to check the employment status of associates. Ultimately, the risk lies with the practice, so it is important to keep a copy of the results of the CEST test as evidence to support the employment status decision (note that the CEST test is anonymous). HMRC should stand by the results of the test, however, critically, the data input into the test must be accurate and reflect the reality of how the relationship operates on a day-to-day basis.

\section{What are the key indicators used when determining employment status?}

The following are some of the factors taken into consideration when determining employment status:

- Does the individual have to do the work themselves, or can they send a substitute?

- Do they risk their own money?

- Do they provide the items of equipment used for their job?

- Can they decide how to do the work?

- How are they paid, eg fixed fee/rate or percentage of income?

- Do/can they work for other practices?

- Do they have to correct unsatisfactory work at their own expense?

- Do they have any management responsibilities?

- Do they have any ownership rights?

It is the overall picture which is considered.

As with the changes to the IR35 rules, HMRC will not be using this change to the guidance as a reason to open up retrospective enquiries into employment status, but associates and practices engaging them should ensure that, going forward, all factors are aligned to minimise the risk should HMRC enquire.

If you have any queries regarding employment status, or would like us to assist with a review for your associate engagements, please do not hesitate to get in touch with a member of the Hazlewoods Dental team.

\section{JAMES MORTER}

Partner

james.morter@hazlewoods.co.uk 01242237661

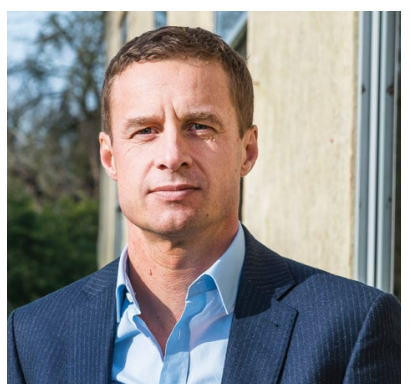

\section{NIGEL UTTING}

Director

nigel.utting@hazlewoods.co.uk 01242680000

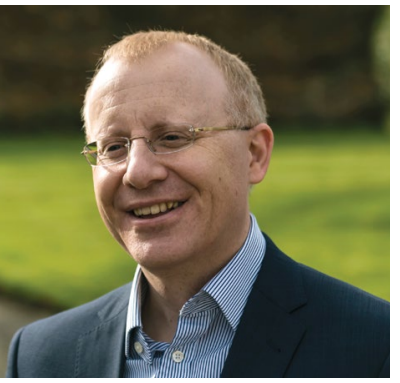

